\title{
STRATEGI PENINGKATAN MUTU PERGURUAN TINGGI AGAMA ISLAM SWASTA (PTAIS) DI LINGKUNGAN KOPERTAIS WILAYAH X JAWA TENGAH (Dalam Perspektif Stakeholders)
}

\author{
Oleh : Rahman El Junusi
}

Fakultas Ekonomi dan Bisnis Islam Universitas Islam Negeri Walisongo Email : rabmaneljunusi@yahoo.co.id

\begin{abstract}
Abstrak
Penyelenggaraan PTAIS di Kopertasis X Jawa tengah terdapat 36 PTAIS yang telah melaksanakan kegiatan proses belajar mengajar, ada 11 PTAIS yang telah mengantongi Akreditasi. Dari sebelas PTAI dapat akreditasi A hanya satu yaitu FT. Unissula. 11 prodi mendapat akreditasi B dan 3 prodi mendapat akreditasi C. Sedangkan yang lain belum mengurus akreditasi Dari data tersebut dapat dilihat fenomena bahwa beberapa PTAIS tidak mempunyai ijin penyelenggaraan pendidikan dan akreditasi. Dari potret tersebut dapat dipahami bahwa kualitas PTAIS masih minim. Oleh karena itu dalam rangka meningkatkan mutu PTAIS diperlukan rumusan strategi peningkatan kinerja PTAIS untuk mencapai visi dan misi PTAI melalui meningkatkan kualitas pendidik dan tenaga. Oleh karena itu peneliti menawarkan konsep balanced scorecad yang bersifat teknis, taktis dan operasional dengan mengimplementasikan prinsisp-prinsip good governance sebagai bahan kebijakan strategi pengembangan PTAIS di masa yang akan datang.
\end{abstract}

Peneliti mengembangkan model balanced scorcard dari Kaplan (1996) yang didasarkan pada perspektif pemangku kepentingan (stakeholders), Adapun tujuan penelitian adalah (1) untuk mengetahui implementasi balanced scorecard pada PTAIS, (2) untuk strategi peningkatan mutu PTAIS berdasarkan pendekatan balanced scorecard kurang baik, hal ini disebabkan bebrapa keterbatasan antara lain : Mahasiswa Baru Sebagian besar PTAIS mengalami penurunan. Jumlah lulusan yang dapat bekerja, Jumlah Kerjasama dengan lembaga lain, Jumlah Penelitian dan publikasi Dosen.

Kata Kunci : Balanced Scorecard; PTAIS; good governance; stakeholders. 


\section{LATAR BELAKANG MASALAH}

Perkembangan Perguruan Tinggi Agama Islam (PTAI) baik negeri maupun swasta secara kuantitatif dari waktu ke waktu sampai saat ini sungguh luar biasa, terdapat 52 Lembaga Perguruan Tinggi Agama Islam Negeri (PTAIN) atau 13,3\% dan 539 Perguruan Tinggi Agama Islam Swasta (PTAIS) atau 86,7\%. Sedangkan di Jawa Tengah tercatat ada satu Institut Agama Islam Negeri (IAIN), lima Sekolah Tinggi Agama Islam Negeri (STAIN) serta 25 lima Perguruan Tinggi Agama Swasta), sehingga keberadaan PTAI mempunyai nilai strategis dalam pembangunan pendidikan nasional. Arah strategi pengembangan perguruan Tinggi Agama Iskam (PTAI) adalah PTAI mampu menghasilkan lulusan yang Islami dan unggul dalam mengintegrasikan keilmuan dengan nilai keislaman. Oleh karen itu penyelenggaraan pendidikan tinggi yang dilaksananakan oleh 52 lembaga PTAIN dan 539 Perguruan Tinggi Agama Islam Swasta harus dilandasi dengan penyelenggaraan pendidikan yang selaras dengan prinsip prinsip profesionalisme dan prinsip good governance yang terintegrasi dalam pembinaan kepribadian dan pengembangan jaringan akademis yang didukung oleh ketersediaan tenaga pendidik yang berkualitas. Ketersediaan tenaga pendidik PTAI berdasarkan kualifikasi pendidikan dapat dijelaskan pada tabel 1. Selain itu Nilai strategis yang dimiliki PTAI masih dihadapkan pada permasalah utama yaitu mutu dan relevansi pendidikan. Menurut Azyumardi Azra (2002) dalam penyelenggaran perguruan tingggi, PTAI masih dihadapkan pada persoalan-persoalan,: (1) standar dan mutu ilmiah di PTAI belum memadai, (2) penguasaan bahasa asing (Inggris dan Arab) belum maksimal, (3) interaksi ilmiah dan edukatif antara dosen dan mahasiswa belum memuaskan, (4) masih banyak dosen yang belum berpegang pada standar-standar ilmiah, dan (5) lemahnya budaya penelitian.

Kondisi ini juga dialami Perguruan Tinggi Agama Islam Swasta (PTAIS) di lingkungan Kopertais wilayah X Jawa Tengah. Berdasarkan data, terdapat 39 PTAIS yang telah melaksanakan kegiatan proses belajar mengajar, ada 11 PTAIS yang telah mengantongi Akreditasi. Dari sebelas PTAI dapat akreditasi A hanya satu yaitu FT. Unissula. 11 prodi mendapat akreditasi B dan 3 prodi mendapat akreditasi C. Sedangkan yang lain belum mengurus akreditasi. Salah satu indikator kualitas akademik dapat dipotret dari akreditasi yang telah diperoleh dari BAN PT. Dari data tersebut dapat 
dilihat fenomena bahwa beberapa PTAIS tidak mempunyai ijin penyelenggaraan pendidikan dan akreditasi.

Dari potret tersebut dapat dipahami bahwa kualitas PTAIS masih minim. Hal ini diperparah juga dengan menurunnya animo masyarakat yang melanjutkan studi di PTAI., rata-rata setiap tahun mengalami penurunan. Dalam rangka peningkatan mutu PTAIS yang kompetensi dan profesionalisme pendidik dan tenaga kependidikan, diperlukan rumusan strategi peningkatan kinerja PTAIS untuk mencapai visi dan misi PTAI melalui meningkatkan kualitas pendidik dan tenaga kependidikan melalui standar kualifikasi pendidikan, peningkatan kompetensi dan profesionalisme menuju tercapainya mutu pendidikan dan tata kelola PTAIS yang bersih dan transparan

Melihat realita di lapangan yang dihadapi oleh PTAIS, maka peneliti menawarkan konsep balanced scorecard berdasarkan perspektif keuangan, pelanggan, proses bisnis internal serta pertumbuhan dan pembelajaran. Perspektif-perspektif ini yang bersifat teknis, taktis dan operasional dengan mengimplementasikan prinsisp-prinsip good governance sebagai bahan kebijakan strategi pengembangan PTAIS di masa yang akan datang. Selama ini balanced scorecard sukses diterapkan pada perusahaan-perusahaan bisnis di Eropa, Amareika dan Australia, oleh peneliti kembangkan sebagai suatu strategi peningkatan mutu pendidikan dan kelembagaan PTAIS dengan harapan dapat terwujudnya penyelenggaraan Pendidikan Tinggi Islam yang menjunjung tinggi nilai-nilai amanah, tafaqquh $f i$ al-din, profesional, tranparan, akuntabel dan berkualitas..

Isu utama dalam peningkatan mutu PTAIS adalah peningkatan kompetensi dan profesionalisme pendidik dan tenaga kependidikan untuk mencapai visi dan misi PTAI melalui meningkatkan kualitas pendidik dan tenaga kependidikan melalui standar kualifikasi pendidikan, peningkatan kompetensi serta profesionalisme. Untuk menuju tercapainya mutu pendidikan dan tata kelola PTAIS yang bersih dan transparan, peneliti menawarkan konsep balanced scorecard yang bersifat teknis, taktis dan operasional dengan mengimplementasikan prinsisp-prinsip good governance sebagai bahan kebijakan strategi pengembangan PTAIS di masa yang akan datang. Selama ini balanced scorecard sukses diterapkan pada perusahaanperusahaan bisnis di Eropa dan Australia, oleh peneliti kembangkan sebagai suatu strategi peningkatan mutu pendidikan dan kelembagaan PTAIS 
dengan harapan dapat terwujudnya penyelenggaraan PTAIS yang menjunjung tinggi nilai-nilai amanah, tafaqquh fi al-din, profesional, transparan, akuntabel dan berkualitas.

Dalam penelitian awal yang dilakukan ada beberapa persoalan yang muncul seputar penyelenggaraan PTAIS Di Lingkungan Kopertais Wilayah $\mathbf{X}$ Jawa Tengah antara lain pada kualitas, potensi, sistem, etos kerja, dana, sarana, dan prasarana, atau persoalan yang berkaitan dengan perannya dalam membangun SDM yang merupakan indikator menentukan standar kualitas PTAIS. Secara tidak langsung, kompetensi out-put dan out come tidak saja akan membawa citra terhadap PTAIS, tetapi secara luas juga terkait erat dengan citra PTAIS dalam menjalankan salah satu kewajibannya, yakni menyelenggarakan PTAIS yang berkualitas.

Berdasarkan realita tersebut, maka diperlukan suatu rumusan kebijakan dalam pengembangan PTAIS yang menitikberatkan pada peningkatan kualitas PTAIS dengan pendekatan balanced scorecard. Balanced scorecard diciptakan untuk menetapkan tujuan dan sekaligus melakukan pengukuran kinerja PTAIS di Lingkungan Kopertais X, sehingga secara langsung sistem ini taktis dan operasional dalam upaya meningkatkan mutu PTAIS yang berdaya saing. Selama ini kebijakan yang diterapkan dalam meningkatkan mutu PTAIS tidak berorientasi pada hasil riset, sehingga kebijakan-kebijakan diterapkan kurang efektif. Oleh karena itu penelitian menawarkan konsep balanced scorecard, dengan harapan strategi ini dapat meningkatkan kualitas pendidik dan tenaga kependidikan serta tata kelola PTAIS yang bersih, trasparan dan akuntabel pada akhirnya dapat meningkatkan kepuasan stakeholders.

Dengan mengembangkan model balanced scorcard dari Kaplan (1996) yang didasarkan pada 5 (lima) perspektif, antara lain: pemangku kepentingan (stakeholders), manajemen administrasi dan keuangan (administration and finance), proses pendidikan dan pengembangan (teaching and learning), etos kerja dan budaya (ethos and culture) dan good governance yang terintegrasi dalam suatu model strategi peningkatan mutu PTAIS. Model balanced scorecard ini sangat tepat di implementasikan pada lembaga Perguruan Tinggi Agama Islam Swasta dalam usaha turut serta dalam mencerdaskan masyarakat serta memberi beberapa kontribusi dalam mewujudkan bangsa yang berdaya saing. Oleh karena itu permasalahan penelitian adalah bagaimana implementasi balanced scorecard dalam upaya meningkatkan mutu PTAIS dalam perspektif stakeholders. 


\section{TINJAUAN PUSTAKA}

\section{Konsep Balanced Scorecard}

Konsep balanced scorecard (BSC) pertama kali diperkenalkan oleh Robert S. Kaplan dan David P. Norton (1992) di dalam artikel Harvard Business Review mereka yang dikutip secara luas sekarang, "Kartu Skor Seimbang Ukuran-ukuran yang Menggerakean Kinerja." Balanced scorecard adalah kartu skor yang digunakan untuk mengukur kinerja dengan memperhatikan keseimbangan antara sisi keuangan dan non keuangan, antara jangka pendek dan jangka panjang serta melibatkan factor internal dan eksternal. Balanced Scorecard adalah alat yang menyediakan pada para manajer pengukuran komprehensif bagaimana organisasi mencapai kemajuan lewat sasaransasaran strategisnya. Metoda ini menjelaskan bagaimana aset intangible dimobilisasi dan dikombinasikan dengan aset intangible dan tangible untuk menciptakan proposisi nilai pelanggan yang berbeda dan hasil finansial yang lebih unggul (Kaplan dan Norton, 2001).

Norton dan Kaplan menempatkan Balanced Scorecard sebagai alat bagi organisasi (untuk mengelola kebutuhan pemegang saham relevannya). Lebih jauh mereka menyarankan Balanced Scorecard sebagai alat untuk memperbaiki aliran informasi dan komunikasi antara top eksekutif dan manajemen menengah dalam perusahaan. Balanced Scorecard ingin memperbaiki sistem konvensional pengontrolan dan akuntansi dengan memperkenalkan fakta lebih kualitatif dan non-finansial.

Menurut Atkinson, Banker, Kaplan and Young (1997) Balance Scorecard adalah : Suatu set dari target dan hasil kinerja yang digunakan sebagai pendekatan untuk mengukur kinerja yang diarahkan kepada gabungan faktor kritis dari tujuan organisasi." Sedangkan Anthony and Govindarajan (1997): menyatakan bahwa Balance Scorecard merupakan Suatu alat sistem untuk memfokuskan perusahaan, meningkatkan komunikasi antar tingkatan manajemen, menentukan tujuan organisasi dan memberikan umpan balik yang terus-menerus guna keputusan yang strategis.

\section{Balanced Scorecard pada Lembaga Pendidikan}

Inti dan konsep balanced scorecard pada lembaga pendidikan yang diwujudkan dalam enam kategori pertama menghasilkan: Pertama Mahasiswa 
hasil belajar harus Berdasarkan Ragam Metode Penilaian dan Merefleksikan keseluruhan organisasi Misi Tujuan dan Peningkatan Diambil bersama Mewakili suatu Holistik Penilaian belajar siswa (pelanggan perspektif). Kedua Mahasiswa dan stakeholder-Fokus Hasil pengukuran kepuasan Harus melibatkan pendidikan khusus program dan layanan pendidikan yang mengarah pada pengembangan hasil belajar siswa serta stakeholder untuk masa depan (perspektif pelanggan). Ketiga Anggaran, keuangan, dan pasar Jika hasil mencakup Instruksional dan pengeluaran administrasi umum melalui Mahasiswa, Biaya Kuliah dan Biaya Tingkat, biaya per Akademik kredit, sumber daya diarahkan kependidikan dari daerah lain, dan beasiswa pertumbuhan (perspektif keuangan). Keempat Fakultas dan staf hasilnya harus-termasuk inovasi dan tarif saran, program pendidikan atau magang di tempat kerja-kinerja perbaikan, pelatihan dan kerja sama tim, pengetahuan dan keterampilan berbagi di banyak bekerja di fungsi, unit, dan lokasi, Kesejahteraan Karyawan, Kepuasan, Ketidakpuasan dan (Belajar dan perspektif pertumbuhan). Kelima Efektivitas Organisasi Hasil, Termasuk kunci internal yang operasional-ukuran kinerja, harus-meliputi: Kapasitas untuk Meningkatkan kinerja pelajar dan mahasiswa pembangunan, iklim pendidikan, Indikator tanggap untuk siswa atau kebutuhan stakeholder, Pemasok dan mitra kinerja, Tindakan Kunci atau indikator pencapaian strategi organisasi, dan rencana aksi (Perspektif proses bisnis internal). Keenam Tata Kelola dan Tanggung Jawab Sosial Jika hasil mencakup internal dan Akuntabilitas eksternal Fiskal, Tindakan atau indikator perilaku etis dan kepercayaan pemangku kepentingan dalam pemerintahan Organisasi, Peraturan dan Hukum Kepatuhan, dan Organisasi Kewarganegaraan (Tata Kelola dan Tanggung Jawab Sosial perspektif).

\section{Implementasi Balanced Scorecard Pada Lembaga Pendidikan}

Dalam penelitian Nomura Research Institute (NRI) Papers No. 45, 1 April 2002 dikemukakan bahwa Jepang sudah beberapa tahun lalu mengintroduksikan pola kerja balance scorecard (Balanced Scorecard) terhadap lebih dari 20 perusahaan (Morisawa, 2002:3). Dari hasil penelitiannya, NRI dapat memberi kesimpulan bahwa berdasarkan pengalaman-pengalaman perusahaan yang menerapkan pengukuran kinerja dengan balanced scorecard tersebut merasakan bahwa balanced scorecard memang memiliki keunggulan yang dirangkum menjadi lima point sebagai berikut: (1) Balanced scorecard dapat digunakan untuk melakukan perbaikan keseimbangan di antara 
sasaran-sasaran jangka pendek, jangka menengah, dan jangka panjang, (2) Dapat menciptakan pemahaman strategi perubahan dengan menyusun atau menetapkan indikator-indikator non-finansial kuantitatif disamping indikator-indikator financial, (3) Mengurangi keragu-raguan atau kekaburan dengan tetap menjaga indikator-indikator non finansial kuantitatif (4)Mempromosikan proses pembelajaran organisasi melalui suatu pengulangan siklus hipotesis verifikasi dan (5) Memperbaiki platform strategi komunikasi secara umum dalam organisasi yang mencerminkan keterkaitan antara pimpinan dan bawahan.

Murphy and Russel (2002:2) menemukan bahwa penggunaan Balanced Scorecard dapat menggantikan Costumer Relationship Management (CRM) Strategi. Hal ini ditunjukkan bahwa lebih dari setengah proyek-proyek CRM tidak menghasilkan nilai tambah apapun bagi perusahaan, dan 50\% dari CRM Strategy tetap saja mengalami kegagalan dalam penerapannya di dunia bisnis, namun Balanced Scorecard dapat menggantikannya.

Meskipun konsep Balanced Scorecard telah telah banyak diadopsi dan digunakan dalam sektor bisnis, sektor pendidikan ternyata belum memeluk Balanced Scorecard konsep luas, seperti ditunjukkan oleh kelangkaan penelitian diterbitkan pada ini topik. Sebuah tinjauan literatur menyeluruh signifikan menghasilkan beberapa publikasi misalnya, Cullen, Joyce, Hassall, dan Broadbent (2003) mengusulkan bahwa seimbang scorecard digunakan dalam pendidikan institusi untuk penguatan pentingnya mengelola bukan hanya pemantauan kinerja. Sutherland (2000) melaporkan bahwa Rossier Sekolah Pendidikan di University of Southern California mengadopsi seimbang pendekatan scorecard untuk menilai akademis program dan proses perencanaan. Chang dan Chow (1999) melaporkan bahwa respon dalam survei dari 69 akuntansi kepala departemen pada umumnya mendukung dari balanced scorecard yang penerapan dan manfaat akuntansi program.

Kajian balanced scorecard dikembangkan dalam program kualitas Baldrige National dengan tujuan membantu bisnis-bisnis Amerika memperbaiki daya saing mereka di dalam pasar global. Bisnis-bisnis bisa memperbaiki daya saing mereka dengan mengidentifikasi organisasiorganisasi model peran, mengenali mereka, dan menyebarluaskan praktekpraktek terbaik mereka di seluruh Amerika Serikat. Program Baldrige diakui secara luas sebagai sebuah faktor yang sangat signifikan didalam memperkuat daya saing AS di pasar global (Program Kualitas Nasional 
Baldrige, 2003a). Implementasi balanced scorecard juga dilakukan pada University of Wisconsin Stout dengan menggunakan indikator dan ukuran sebagai berikut: (1) Dimensi Student-learning results/Siswa hasil belajar; (2) Dimensi Student and stakeholder focused results/Mahasiswa dan stakeholder terfokus hasil; (3) Dimensi Budgetary and financial results; (4) Dimensi Faculty and staff results dan (5) Dimensi Organizational effectiveness results.

\section{METODE PENELITIAN}

Penelitian tentang strategi peningkatan mutu PTAIS di lingkungan Kopertais Wilayah X Jawa Tengah yang berjumlah 39 (tiga puluh sembilan) Perguruan Tinggi. Metode pengumpulan data yang digunakan adalah : Pertama, wawancara, yaitu mengadakan tanya jawab langsung dengan responden maupun pihak-pihak yang terkait. Kedua, metode angket, metode ini mendasarkan pada laporan tentang diri atau self report, atau setidak-tidaknya pada pengetahuan dan atau keyakinan pribadi. Pelaksanaan metode angket dalam penelitian ini adalah penyebaran kuesioner pada responden secara langsung khususnya berkaitan dengan good governance etos kerja dan budaya kerja dan Ketiga, dokumentasi berupa data kemahasiswaan, kepegawaian dan keuangan strategi peningkatan mutu PTAIS.

Agar penelitian ini dapat dilakukan sesuai dengan yang diharapkan, perlu dipahami unsur-unsur yang menjadi dasar dari suatu penelitian ilmiah, yaitu variabel, indikator empirik dan pengukurannya. Dalam penelitian ilmiah, suatu konsep akan dijabarkan kembali ke dalam suatu bentuk yang dapat dipahami dan diuji tingkat validitas dan reliabilitasnya. Agar konsep tersebut dapat diteliti secara empirik perlu dioperasionalisasikan dengan cara mengubah dan menjabarkannya menjadi suatu variabel atau sub variabel.

Operasional variabel balanced scorecard, indicator dan pengukuran dapat dilihat pada tabel 1.

Tabel 1. Instrumen dan Sumber Data

\begin{tabular}{|l|l|}
\hline \multicolumn{1}{|c|}{ Instrumen } & \multicolumn{1}{c|}{ Sumber Data } \\
\hline Peningkatan jumlah mahasiswa yg diterima & Dokumen \\
\hline Peningkatan jumlah lulusan & Dokumen \\
\hline Peningkatan lulusan yg dapat bekerja/berusaha & Dokumen \\
\hline Peningkatan instansi yang menggunakan lulusan & Dokumen \\
\hline Peningkatan hasil Penelitian oleh Dosen & Dokumen \\
\hline
\end{tabular}




\begin{tabular}{|l|l|}
\hline \multicolumn{1}{|c|}{ Instrumen } & \multicolumn{1}{c|}{ Sumber Data } \\
\hline Peningkatan publikasian hasil penelitian & Dokumen \\
\hline
\end{tabular}

Sumber : data penelitian

Metode untuk menganalisis data dalam penelitian ini, sesuai dengan tujuan penelitian digunakan metode analisis deskriptif kuantitatif eksplantif dan komperatif, yaitu dengan menggambarkan dan menjelaskan secara mendalam tentang implementasi balanced scorecard pada masing-masing PTAIS di Lingkungan Kopertais X Jawa Tengah dalam perspektif stakeholders.

\section{HASIL PENELITIAN DAN PEMBAHASAN}

Untuk menerapkan balanced scorecard pada PTAIS tentunya memerlukan data dan dokumen yang akurat, hal ini untuk mengetahui perubahan-perubahan pada indikator kunci yang dapat dijadikan sebagai bukti dasar kegiatan organisasi. Realita di lapangan banyak sekali yang tidak terdokumentasi dengan baik sehingga dalam perspektif stakeholders masih terdapat beberapa kelemahan-kelemahan. Hal ini merupakan salah satu kendala terbesar dalam mengimplementasikan balanced scorecard dan melaksanakan ukuran-ukuran atau indikator kunci Balanced scorecard pada PTAIS karena data yang dikumpulkan tidak sesuai dengan yang diharapkan, data yang dibutuhkan untuk memantau perubahan nilai-nilai indikator yang dipilih dan untuk menyediakan informasi yang tepat waktu untuk manajemen kinerja dapat dikumpulkan hanya jika proses pengumpulan data di dalam PTAIS tersedia sesuai standar menjadi kegiatan berkelanjutan, sebagai bagian integral dari sehari-hari seperti halnya organisasi bisnis.

Untuk mengetahui implementasi balanced scorecard dalam upaya peningkatan mutu PTAIS dapat dijelaskan pada tabel berikut

Table 2. Perkembangan Jumlah Mahasiswa Baru

\begin{tabular}{|c|l|c|c|c|c|}
\hline \multirow{2}{*}{ No. } & \multirow{2}{*}{ PTAIS } & \multicolumn{3}{c|}{ Jumlah Mhs Baru } & Ket \\
\cline { 3 - 6 } & & $\mathbf{2 0 1 1}$ & $\mathbf{2 0 1 2}$ & $\mathbf{2 0 1 3}$ & $\mathbf{\%}$ \\
\hline 1 & UNU Surakarta & 343 & 295 & 409 & 19.24 \\
\hline 2 & UNISSULA & 231 & 220 & 217 & $(6.06)$ \\
\hline 3 & STAIMUS & 501 & 207 & 216 & $(56.89)$ \\
\hline 4 & UMS & 267 & 160 & 150 & $(43.82)$ \\
\hline 5 & STAINU Temanggung & 127 & 105 & 78 & $(38.58)$ \\
\hline 6 & STAINU Kebumen & 282 & 365 & 420 & 48.94 \\
\hline
\end{tabular}




\begin{tabular}{|c|l|c|c|c|c|}
\hline \multirow{2}{*}{ No. } & \multirow{2}{*}{ PTAIS } & \multicolumn{3}{c|}{ Jumlah Mhs Baru } & Ket \\
\cline { 3 - 6 } & & $\mathbf{2 0 1 1}$ & $\mathbf{2 0 1 2}$ & $\mathbf{2 0 1 3}$ & $\mathbf{\%}$ \\
\hline 7 & UNDARIS Ungaran & 98 & 67 & 113 & 15.31 \\
\hline 8 & SETIA WS & 397 & 402 & 415 & 4.53 \\
\hline 9 & STAI Pati & 271 & 287 & 298 & 9.96 \\
\hline 10 & UNSIQ & 875 & 920 & 934 & 6.74 \\
\hline 11 & IAIIG Cilacap & 147 & 284 & 195 & 32.65 \\
\hline 12 & INISNU Jepara & 506 & 577 & 558 & 10.28 \\
\hline 13 & STAIM Cepu & 249 & 296 & 225 & $(9.64)$ \\
\hline 14 & STAIM Klaten & 100 & 95 & 90 & $(10.00)$ \\
\hline 15 & STAI Grobogan & 126 & 100 & 80 & $(36.51)$ \\
\hline 16 & STIKAP YMI Pekalongan & 153 & 123 & 54 & $(64.71)$ \\
\hline
\end{tabular}

Sumber : Data primer diolah

Berdasarkan tabel 2 menunjukkan bahwa dari 17 PTAIS yang menjadi sampel penelitian 50 persen mengalami kenaikan jumlah mahasiswa baru sedangkan 50 persen lainnya mengalami penurunan. Kenaikan mahasiswa terbesar pada STAINU Kebumen (48,94 dan IAIIG Cilacap sebesar 32,65, sedangkan PTAIS yang mengalami penurunan terbesar adalah STIKAP YMI Pekalongan dan STAIMUS yang rata-rata mengalami penurunan lebih dari 50\%. Dari jawaban responden menyatakan bahwa pencapaian mahasiswa baru 3 tahun terakhir kurang sesuai 40 persen, sangat tidak sesuai 45 persen sedangkan 5 persen menyatakan sesuai.

Tabel 3. Jumlah Lulusan yang Bekerja/Berusaha

\begin{tabular}{|c|l|c|c|c|c|}
\hline \multirow{2}{*}{ No. } & \multirow{2}{*}{ PTAIS } & \multicolumn{3}{c|}{$\begin{array}{c}\text { Lulusan Yang } \\
\text { Bekerja }\end{array}$} & Ket \\
\cline { 3 - 6 } & & $\mathbf{2 0 1 1}$ & $\mathbf{2 0 1 2}$ & $\mathbf{2 0 1 3}$ & Rata-Rata \\
\hline 1 & UNU Surakarta & 91 & 90 & 91.5 & 90.83 \\
\hline 2 & UNISSULA & 75 & 75 & 75 & 75.00 \\
\hline 3 & STAIMUS & 40 & 60 & 65 & 55.00 \\
\hline 4 & UMS & 35 & 75 & 75 & 61.67 \\
\hline 5 & STAINU Temanggung & 71 & 81 & 65 & 72.33 \\
\hline 6 & STAINU Kebumen & 70 & 98 & 90 & 86.00 \\
\hline 7 & UNDARIS Ungaran & 75 & 80 & 80 & 78.33 \\
\hline
\end{tabular}




\begin{tabular}{|c|l|c|c|c|c|}
\hline 8 & SETIA WS & 90 & 95 & 95 & 93.33 \\
\hline 9 & STAI Pati & 75 & 75 & 95 & 81.67 \\
\hline 10 & UNSIQ & 90 & 85 & 75 & 83.33 \\
\hline 11 & IAIIG Cilacap & 75 & 80 & 85 & 80.00 \\
\hline 12 & INISNU Jepara & 65 & 60 & 50 & 58.33 \\
\hline 13 & STAIM Cepu & 96 & 96 & 96 & 96.00 \\
\hline 14 & STAIM Klaten & 98 & 95 & 100 & 97.67 \\
\hline 15 & STAI Grobogan & 0 & 0 & 0 & - \\
\hline 16 & STIKAP YMI Pekalongan & 0 & 0 & 0 & - \\
\hline
\end{tabular}

Sumber : Data primer diolah

Berdasarkan tabel 3 menunjukkan bahwa 63,5 persen PTAIS di wilayah Kopertais X lulusannya terserap dipasar kerja atau bekerja diatas 75 persen, sedangkan 37,5 persen lulusannya yang bekerja dibawah $75 \%$. sedangkan STAI Grobogan dan STIKAP YMI Pekalongan 0 persen karena belum meluluskan.

Tabel 4. Jumlah Kerjasama PTAIS dengan Lembaga Lain

\begin{tabular}{|c|l|c|c|c|c|}
\hline \multirow{2}{*}{ No } & \multirow{2}{*}{ PTAIS } & \multicolumn{3}{c|}{ Kerjasama } & Ket \\
\cline { 3 - 6 } & & $\mathbf{2 0 1 1}$ & $\mathbf{2 0 1 2}$ & $\mathbf{2 0 1 3}$ & $\mathbf{\%}$ \\
\hline 1 & UNU Surakarta & 11 & 11 & 11 & - \\
\hline 2 & UNISSULA & 20 & 21 & 21 & 5.00 \\
\hline 3 & STAIMUS & 10 & 12 & 13 & 30.00 \\
\hline 4 & UMS & 0 & 0 & 0 & - \\
\hline 5 & STAINU Temanggung & 6 & 6 & 12 & 100.00 \\
\hline 6 & STAINU Kebumen & 39 & 46 & 52 & 33.33 \\
\hline 7 & UNDARIS Ungaran & 7 & 0 & 0 & $(100.00)$ \\
\hline 8 & SETIA WS & 5 & 9 & 15 & 200.00 \\
\hline 9 & STAI Pati & 41 & 43 & 44 & 7.32 \\
\hline 10 & UNSIQ & 15 & 17 & 21 & 40.00 \\
\hline 11 & IAIIG Cilacap & 10 & 12 & 15 & 50.00 \\
\hline 12 & INISNU Jepara & 30 & 38 & 40 & 33.33 \\
\hline 13 & STAIM Cepu & 34 & 37 & 41 & 20.59 \\
\hline 14 & STAIM Klaten & 16 & 16 & 16 & - \\
\hline
\end{tabular}




\begin{tabular}{|c|l|c|c|c|c|}
\hline \multirow{2}{*}{ No } & \multirow{2}{*}{ PTAIS } & \multicolumn{3}{|c|}{ Kerjasama } & Ket \\
\cline { 3 - 6 } & & $\mathbf{2 0 1 1}$ & $\mathbf{2 0 1 2}$ & $\mathbf{2 0 1 3}$ & $\mathbf{\%}$ \\
\hline 15 & STAI Grobogan & 0 & 0 & 0 & - \\
\hline 16 & STIKAP YMI Pekalongan & 3 & 3 & 4 & 33.33 \\
\hline
\end{tabular}

Sumber : Data primer diolah

Tabel 4 menunjukkan rata-rata PTAIS melakukan kerjasama meningkat dari tahun ketahun, kecuali UNISSULA mengalami penurunan dari tahun 2011 7 lembaga sedangkan tahun 2013 tidak ada sama sekali kerjasama dengan lembaga lain. Sedangkan UNU Surakarta dan STAIM Klaten tetap dan STAI Grobogan belum sama sekali menjalin kerjasama dengan lembaga lainnya.

Tabel 5. Jumlah Anggaran Penelitian Dosen PTAIS

\begin{tabular}{|c|l|c|c|c|c|}
\hline \multirow{2}{*}{ No } & \multirow{2}{*}{ PTAIS } & \multicolumn{3}{c|}{$\begin{array}{c}\text { Anggaran } \\
\text { Penelitian (jutan) }\end{array}$} & Ket \\
\cline { 3 - 6 } & & $\mathbf{2 0 1 1}$ & $\mathbf{2 0 1 2}$ & $\mathbf{2 0 1 3}$ & Rata-rata \\
\hline 1 & UNU Surakarta & 102 & 97.5 & 172 & 124 \\
\hline 2 & UNISSULA & 22.5 & 22.5 & 22.5 & 23 \\
\hline 3 & STAIMUS & 40 & 45 & 50 & 45 \\
\hline 4 & UMS & 31 & 31 & 37.5 & 33 \\
\hline 5 & STAINU Temanggung & 6 & 6 & 12 & 8 \\
\hline 6 & STAINU Kebumen & 31 & 7 & 10 & 16 \\
\hline 7 & UNDARIS Ungaran & 10 & 2 & 5 & 6 \\
\hline 8 & SETIA WS & 45 & 45 & 45 & 45 \\
\hline 9 & STAI Pati & 0 & 0 & 0 & - \\
\hline 10 & UNSIQ & 15 & 17 & 21 & 18 \\
\hline 11 & IAIIG Cilacap & 18 & 18 & 18 & 18 \\
\hline 12 & INISNU Jepara & 65 & 75 & 100 & 80 \\
\hline 13 & STAIM Cepu & 61 & 80 & 90 & 77 \\
\hline 14 & STAIM Klaten & 10 & 15 & 75 & 33 \\
\hline 15 & STAI Grobogan & 5 & 5 & 5 & 5 \\
\hline 16 & STIKAP YMI Pekalongan & 5 & 5 & 5 & 5 \\
\hline
\end{tabular}

Sumber : Data primer diolah 
Tabel 5 menunjukkan rata-rata jumlah anggaran penelitian dosen PTAIS sebesar 33,45 juta, jadi hanya 5 PTAIS atau 31 persen yang menyediakan anggaran penelitian diatas rata-rata sedangkan 69 persen dibawah rata-rata dan bahkan STAI Pati tidak menyediakan dana penelitian untuk dosen.

Tabel 6. Jumlah Penelitian Dosen PTAIS

\begin{tabular}{|c|l|c|c|c|c|}
\hline \multirow{2}{*}{ No } & \multirow{2}{*}{ PTAIS } & \multicolumn{3}{c|}{$\begin{array}{c}\text { Jumlah Penelitian } \\
\text { Dosen }\end{array}$} & Ket \\
\cline { 3 - 6 } & & $\mathbf{2 0 1 1}$ & $\mathbf{2 0 1 2}$ & $\mathbf{2 0 1 3}$ & rata-rata \\
\hline 1 & UNU Surakarta & 12 & 7 & 7 & 9 \\
\hline 2 & UNISSULA & 21 & 23 & 25 & 23 \\
\hline 3 & STAIMUS & 12 & 12 & 16 & 13 \\
\hline 4 & UMS & 18 & 24 & 20 & 21 \\
\hline 5 & STAINU Temanggung & 1 & 3 & 1 & 2 \\
\hline 6 & STAINU Kebumen & 23 & 25 & 31 & 26 \\
\hline 7 & UNDARIS Ungaran & 10 & 2 & 5 & 6 \\
\hline 8 & SETIA WS & 2 & 1 & 1 & 1 \\
\hline 9 & STAI Pati & 0 & 0 & 0 & - \\
\hline 10 & UNSIQ & 10 & 15 & 12 & 12 \\
\hline 11 & IAIIG Cilacap & 8 & 12 & 9 & 10 \\
\hline 12 & INISNU Jepara & 7 & 10 & 13 & 10 \\
\hline 13 & STAIM Cepu & 10 & 11 & 13 & 11 \\
\hline 14 & STAIM Klaten & 2 & 3 & 3 & 3 \\
\hline 15 & STAI Grobogan & 2 & 2 & 2 & 2 \\
\hline 16 & STIKAP YMI Pekalongan & 0 & 3 & 3 & 2 \\
\hline
\end{tabular}

Sumber : Data primer diolah

Tabel 6 menunjukkan rata-rata jumlah penelitian yang dihasilkan oleh dosen PTAIS masih minim, bahkan STAI Pati tidak menghasilkan satupun penelitian. Sedangkan UMS rata rata menghasilkan publikasi penelitian sebanyak 21 judul dan Unissula 23 judul.

Tabel 7. Jumlah Publikasi Penelitian Dosen PTAIS

\begin{tabular}{|c|c|c|c|c|c|}
\hline \multirow{3}{*}{ No } & \multirow{2}{*}{ PTAIS } & \multicolumn{3}{|c|}{$\begin{array}{c}\text { Jumlah Publikasi } \\
\text { Penelitian }\end{array}$} & Ket \\
\cline { 3 - 6 } & & 2010 & 2011 & 2012 & rata-rata \\
\hline
\end{tabular}




\begin{tabular}{|c|l|c|c|c|c|}
\hline 1 & UNU Surakarta & 21 & 18 & 22 & 20 \\
\hline 2 & UNISSULA & 30 & 30 & 30 & 30 \\
\hline 3 & STAIMUS & 7 & 9 & 12 & 9 \\
\hline 4 & UMS & 37 & 35 & 40 & 37 \\
\hline 5 & STAINU Temanggung & 1 & 3 & 1 & 2 \\
\hline 6 & STAINU Kebumen & 5 & 7 & 6 & 6 \\
\hline 7 & UNDARIS Ungaran & 1 & 0 & 0 & 0 \\
\hline 8 & SETIA WS & 2 & 2 & 2 & 2 \\
\hline 9 & STAI Pati & 0 & 0 & 0 & - \\
\hline 10 & UNSIQ & 25 & 28 & 30 & 28 \\
\hline 11 & IAIIG Cilacap & 0 & 0 & 0 & - \\
\hline 12 & INISNU Jepara & 7 & 24 & 20 & 17 \\
\hline 13 & STAIM Cepu & 12 & 16 & 19 & 16 \\
\hline 14 & STAIM Klaten & 1 & 1 & 1 & 1 \\
\hline 15 & STAI Grobogan & 0 & 1 & 0 & 0 \\
\hline 16 & STIKAP YMI Pekalongan & 0 & 0 & 0 & - \\
\hline
\end{tabular}

Sumber : Data primer diolah

Tabel 7 menunjukkan rata-rata jumlah publikasi penelitian yang dihasilkan oleh dosen PTAIS masih minim, bahkan STAI Pati tidak menghasilkan satupun publikasi penelitian antara lain STAI Pati, IAIIG Cilacap, STAI Grobogan dan STIKAP YMI Pekalongan. Sedangkan UMS rata rata menghasilkan publikasi penelitian sebanyak 37 judul dan Unissula 30 judul.

\section{KESIMPULAN}

Dalam implementasi balanced scorecard pada PTAI dalam hal ini PTAIS, mengalami banyak kendala antara lain karakteristik PTAI berbeda dengan karakterisitik yang dimiliki oleh perusahaan. Untuk menerapkan balanced scorecard pada PTAIS tentunya memerlukan data dan dokumen yang akurat, hal ini untuk mengetahui perubahan-perubahan pada indikator kunci yang dapat dijadikan sebagai bukti dasar kegiatan organisasi. Realita dilapangan banyak sekali yang tidak terdokumentasi dengan baik sehingga dari berbagai perspektif masih terdapat beberapa kelemahan-kelemahan. Hal ini merupakan salah satu kendala terbesar dalam mengimplementasikan balanced scorecard dan melaksanakan ukuran-ukuran atau indikator kunci balanced scorecard pada PTAI atau PTAIS karena data yang dikumpulkan 
tidak sesuai dengan yang diharapkan, data yang dibutuhkan untuk memantau perubahan nilai-nilai indikator yang dipilih dan untuk menyediakan informasi yang tepat waktu untuk manajemen kinerja dapat dikumpulkan hanya jika proses pengumpulan data di dalam PTAI tersedia sesuai standar menjadi kegiatan berkelanjutan, sebagai bagian integral dari sehari-hari seperti halnya organisasi bisnis.

Balanced scorecard dapat diterapkan pada PTAIS sebagai lembaga pendidikan tinggi Islam, jika syarat-syarat tersebut terpenuhi. Karena PTAIS tidak lepas dari karakteristik-karakteristik lembaga pendidikan Tinggi Islam, dimana sistem administrasi, manajemen dan bentuk laporan keuangannya masih didasarkan pada Standar akuntansi pemerintah (SAP) sehingga implemetasi balanced scorecard mengalami banyak kendala. Jadi pada hakekatnya implementasi balanced scorecard pada PTAIS dapat dilakukan berdasarkan kajian-kajian dari aspek stakeholders

Berdasarkan pembahasan menunjukkan bahwa implementasi Balanced Scorecard Dalam Perspektif Pemangku Kepentingan (Stakeholders) Pada PTAIS di Wilayah Kopertais X Jawa Tengah dapat disimpulkan kurang baik, hal ini disebabkan dari beberapa indikator antara lain: (1) Indikator Jumlah Mahasiswa Baru Sebagian besar PTAIS mengalami penurunan; (2)Indikator Jumlah Mahasiswa Keseluruhan Sebagian besar PTAIS mengalami penurunan; (3) Jumlah lulusan yang dapat bekerja masih terbatas, (4) jumlah Kerjasama masih terbatas, (4) Jumlah Penelitian Dosen masih kurang dibandingkan dengan jumlah dosen yang ada, dan jumlah Publikasi Penelitian Dosen masih kurang dibandingkan dengan jumlah dosen yang ada.

Oleh karena itu, untuk meningkatkan perspektif ini diperlukan strategi peningkatan mutu PTAIS terutama strategi peningkatan jumlah mahasiswa dengan cara meningkatkan kualitas, promosi, peningkatan kerjasama, penerapan penjaminan mutu, peningkatan penelitian dosen serta peningkatan publikasi ilmiah. Hal ini akan berdampak pada peningkatan mutu PTAIS, yang pada akhirnya akan meningkatkan animo masyarakat untuk melanjutkan studi pada PTAIS. 


\section{DAFTAR PUSTAKA}

Averson, Paul (25 Agustus 2011), "A Balanced Scorecard for City \& County Services", http: \\www.balanced scorecard.org.

Averson, Paul (25 Agustus 2011), "Building a Government Balanced Scorecard: Phase 2 -Implementation and Automation”, http:\\www.balanced scorecard.org.

Balanced Scorecard as a Control System for Monitoring and Revising Corporate Strategy", http: \\www.ssrn.com, 12 Februari 2011.

Baldrige National Quality Program (2003), Education Criteria for performance Excellent, www.quality.nist.gov

Cullen, J., Joyce, J., Hassal, T., \& Broadbent , M. (2003). Quality in higher education: From monitoring to management. Quality Assurance in Education, 11(1), 5-14.

Gazperz, Vincent, 2002. Sistem Pengukuran Kinerja Terintegrasi Balanced Scorecard dengan six sigma untuk organisasi pemerintah, Jakarta, Gramedia Pustaka Utama.

Giri, Efraim Ferdinan. Januari-April 1998. "Balanced Scorecard: Suatu Sistem Pengukuran Kinerja Strategik." Kajian Bisnis, No 13, 35-46.

Hansen D. R., Maryanne M. Mowen (2003), $7^{\text {th }}$ edition. Cost Accounting. Cincinnati, Ohio: South-Western Publishing, Co.

Julianto, Heppy, 2000, Mengukur Kepuasan Pelanggan , Manajemen, No 138, Februari, pp 34-35

Kaplan, R. and Norton, D., "Putting the balanced scorecard to work", Harvard Business Review, September-October 1993, pp. 134-142

Kaplan, R. and Norton, D., "The balanced scorecard - measures that drive performance", Harvard Business Review, January-February 1992, pp. 71 79

Kaplan, R. and Norton, D., "Using the balanced scorecard as a strategic management system", Harvard Business Review, January-February 1996a, pp. 75-85

Kaplan, R. and Norton, D., The balanced scorecard: translating a strategy into action, Harvard Business School press, Boston, 1996b

Kaplan, Robert S and David P Norton, 1993. "Putting the Balanced Scorecard to Work”, Harvard Business Review.

Kaplan, Robert S and David P Norton, 1996. Balanced Scorecard: Menerapkan Strategi Menjadi Aksi, Erlangga : Jakarta.

Kaplan, Robert S dan David P. Norton, 1996, Balanced Scorecard: Translating Strategy Into Action, Boston: Havard Business School Press.

Laela, Fatma. 1998. "Balanced Scorecard : Sebagai Alternatif Pengukuran Kinerja Manajemen.” Jurnal Teknologi Bisnis, vol.2 No.1, 
Lasdi, Lodovicus. Agustus 2002. Balanced Scorecard Sebagai Rerangka Pengukuran Kinerja Perusabaan Secara Komprehensif dalam Lingkungan Bisnis Global. Jurnal Widya Manajemen dan Akuntansi, vol.2 No.2, 150-169,

Mahmudi. 2007. Manajemen Kinerja Sektor Publik, UPP STIM YKPN : Yogyakarta.

Malina, Mary, A. dan Selto, Frank, H. (8 Februari 2011),"Communicating and Controlling Strategy: an Emperical Study of the Effectiveness of the Balanced Scorecard", http: \\www.ssrn.com.

Mulyadi dan Setyawan Jhony. 2001. Sistem Perencanaan dan Pengendalian manajemen: Sistem Pelipatgandaan Kinerja Keuangan Perusahaan, Salemba Empat : Jakarta.

Mulyadi, Strategic Management System Dengan Pendekatan Balanced Scorecard (Bagian Akhir Dari Dua Tulisan), Usahawan, No 03, Tahun XXVIII, Maret, Halaman 36-41.

Mulyadi, 1999, Sistem Perencanaan Dan Pengendalian Manajemen, Yogyakarta: Aditya Media.

Mulyadi, 1999, Strategic Management System Dengan Pendekatan Balanced Scorecard (Bagian Pertama Dari Dua Tulisan), Usahawan, No. 02, Tahun XXVIII, Februari, Halaman 39-46.

Mulyadi, Balanced Scorecard, Salemba Empat, Universitas Gajah Mada, 2001

Mulyadi. 2001. Balanced Scorecard : Alat Manajemen Kontemporer untuk Pelipatgandaan Kinerja Keuangan Perusahaan, Salemba Empat : Jakarta.

Rohm, Howard (25 Agustus 2011), "Improve Public Sector results With A Balanced Scorecard: Nine Steps To Succeess", http: \\www.balancedscorecard.org.

Sekaran, U. 2003. Research Methods for Business: A Skill Building Approach $2^{\text {nd }}$ Edition, John Wiley and Son. New York pp. 265-266

Soetjipto, Budi W, 1997, Mengukur Kinerja Bisnis Dengan Balanced Scorecard, Usahawan, No 06, Tahun XXVI, Juni, pp. 21-25.

Sumarni, Murti dan John Soeprihanto. 1998. Pengantar Bisnis. Liberty : Yogyakarta.

Sutherland, V. dan Cary L. Cooper. (2000). Strategic Stress management. London : Macmillan

Yuwono, Sony, 2002. Petunjuk Praktis Penyusunan Balanced Scorecard: Menuju Organisasi Yang Berfokus Pada Strategi, Jakarta, PT Gramedia Pustaka Utama.

Zaeni. Desember 2000. "Strategi Pengukuran Kinerja Sektor Publik dengan Rerangka Balanced Scorecard." MGS, vol.5 No.32, 13-38. 